\title{
Fuel economy and emissions analysis of conventional diesel, diesel-electric hybrid, biodiesel and natural gas powered transit buses
}

\author{
A. C. Nix, J. A. Sandoval, W. S. Wayne, N. N. Clark \\ \& D. L. McKain \\ Center for Alternative Fuels, Engines and Emissions (CAFEE), \\ Department of Mechanical and Aerospace Engineering, \\ West Virginia University, USA
}

\begin{abstract}
Alternative fuels, emissions control technologies and advanced propulsion technologies offer great potential for reducing emissions from, and increasing fuel economy of, buses employed in public transportation. The use of fuels such as Compressed Natural Gas (CNG) and biodiesel, emissions controls such as diesel particulate filters (DPF) and diesel oxidation catalysts (DOC), and the use of advanced propulsion systems such as hybrid-electric diesel have great potential for decreasing emissions from public transit vehicles and potentially increasing fuel economy. The focus of this paper is to assess the environmental benefits of alternative fuels and advanced hybrid drive technologies in transit vehicles through experimental testing and analysis.

Results show that hybrid-electric diesel and $\mathrm{CNG}$ buses yield significant reductions in $\mathrm{CO}_{2}$ emissions, approximately 10-20\% lower than conventional diesel. Stoichiometric $\mathrm{CNG}$ buses demonstrated extremely low emissions of $\mathrm{NO}_{x}$, while conventional, lean-burn $\mathrm{CNG}$ had the highest $\mathrm{NO}_{\mathrm{x}}$ emissions, approximately twice that of hybrid technologies and conventional diesel engines. The hybrid-electric technology demonstrated the highest fuel economy, while CNG has the lowest fuel economy. The use of a $20 \%$ biodiesel blend (B20) demonstrated no discernable differences in fuel economy, while showing slightly higher $\mathrm{NO}_{\mathrm{x}}$ emissions levels and significantly lower PM compared to conventional diesel.
\end{abstract}

Keywords: transit buses, alternative fuels, hybrid-electric vehicles, fuel economy, emissions, emissions controls. 


\section{Introduction}

Alternative fuels, emissions control technologies and advanced propulsion technologies offer great potential for reducing emissions from, and increasing fuel economy of, buses employed in public transportation. The use of fuels such as compressed natural gas (CNG) and biodiesel, emissions controls such as diesel particulate filters (DPF) and diesel oxidation catalysts (DOC), and the use of advanced propulsion systems, such as electric-hybrids, have great potential for decreasing emissions from public transit vehicles and potentially increasing fuel economy.

The number of transit buses in the United States was 62,000 in 2009 and the fleet is increasing at a rate of approximately $1 \%$ per year [1]. In the U.S., transit buses account for approximately $44 \%$ of the passenger miles traveled and $73 \%$ of the fossil fuels consumed by public transportation [1]. Although at the macroscale level emissions from transit buses are small in comparison to the total emissions by motor vehicles, their impact at the microscale level (population exposure and related health effects) is significant as they operate in metropolitan areas, many of which are in non-attainment regions with respect to ambient air quality $[1,2]$. The focus of this paper is to assess the environmental benefits of increased implementation of alternative fuels and advanced hybrid drive technologies in the U.S. transit bus fleet, which is applicable to bus transit fleets in cities around the world, in comparison to continued reliance upon diesel fuel, primarily to reduce tailpipe emissions of air pollutants harmful to public health and the environment.

The West Virginia University (WVU) Center for Alternative Fuels, Engines and Emissions (CAFEE) has developed a comprehensive database of emissions and fuel economy measurements from various transit bus technologies through testing with their Transportable Heavy-Duty Vehicle Emissions Test Laboratory (THDVETL) [3]. The mobile laboratory has been employed to test vehicles for various public transportation authorities throughout North America, including the United States and Mexico. Data have been reported in various publications and reports over the past decade [1,4-7]. The research has been sponsored by public transportation authorities, and U.S. government agencies including the Department of Transportation (DOT), Federal Transit Administration (FTA), Department of Energy (DOE) and Environmental Protection Agency (EPA). Characterization of vehicles was performed on a chassis dynamometer that simulated inertial, aerodynamic, and tire rolling resistance loads, based on vehicle acceleration and speed of a specific drive cycle (speed versus time schedule) [3]. WVU CAFEE has developed drive cycles for a wide range driving situations representative of vehicle use in transit bus operations. Testing was conducted in accordance with emissions test procedures set forth by the U.S. EPA in the Code of Federal Regulations Title 40 Part 86 Subparts B and N [8] and Part 1065 [9] and SAE recommended practice for testing of hybrid-electric vehicles [10]. The exhaust from each bus was routed to a full-scale dilution tunnel where gaseous and particulate emissions were sampled and measured. Analysis of data from the laboratory results in quantification of fuel economy 
and emissions of oxides of nitrogen $\left(\mathrm{NO}_{\mathrm{x}}\right)$, carbon dioxide $\left(\mathrm{CO}_{2}\right)$, carbon monoxide (CO), hydrocarbons (methane and non-methane hydrocarbons $(\mathrm{NMHC})$ ) and particulate matter (PM). Results and emissions trends are reported for $40 \mathrm{ft}$ and $60 \mathrm{ft}$ articulated buses of varying engine model year and propulsion technologies.

\section{Drive cycles, coastdowns, and laboratory operation}

\subsection{Drive cycles}

In order to quantify the emissions and fuel economy of the test vehicles, the vehicles were driven on the engine dynamometer through a cycle representative of typical operation of the transit buses in revenue service. The transient speedtime schedule test cycle used to evaluate the exhaust emissions and fuel economy of the test buses for the current work was the Orange County Transportation Authority (OCTA) driving cycle. This cycle represents transit fleet operation near the Los Angeles metropolitan area. Data was also recorded for the Washington Metropolitan Area Transit Authority (WMATA) cycle; however, results for all buses in this study were only available on the OCTA cycle, so only this cycle was reported herein.

The target speed versus time trace for the OCTA duty cycle is shown in Figure 1 below, with the relevant statistical properties. In general, the OCTA cycle compared to a cycle within metropolitan city limits (such as the WMATA cycle) is a higher speed cycle with significantly less idle time and correspondingly fewer stops per mile which impact emissions and fuel economy on a given vehicle. WVU faculty and students developed or assisted in the development of these cycles by installing GPS equipment and engine control unit (ECU) logging equipment on in-use buses to characterize their routes. During testing, the driver of the vehicle on the chassis dynamometer follows the speed versus time trace for the applicable cycle via a monitor installed in the vehicle. The speed set point trace is followed as closely as possible and the actual calculated vehicle speed is displayed.

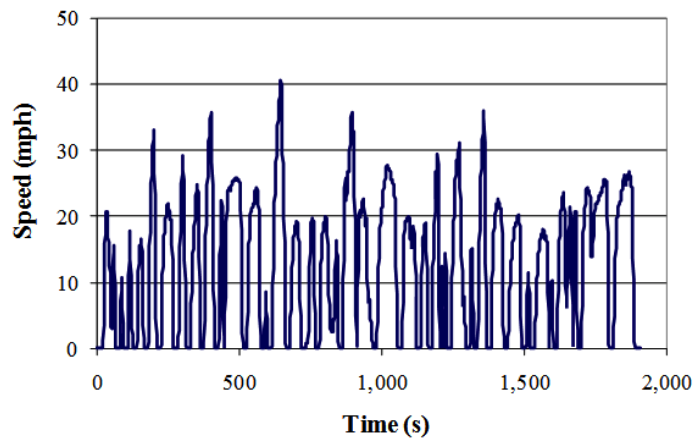

\begin{tabular}{|l|c|c|}
\hline \multicolumn{1}{|c|}{ Statistic } & OCTA & WMATA \\
\hline Time (s) & 1,909 & 1,839 \\
\hline Distance (mi) & 6.54 & 4.26 \\
\hline $\begin{array}{l}\text { Average } \\
\text { Speed(mph) }\end{array}$ & $\mathbf{1 2 . 3 3}$ & $\mathbf{8 . 3 4}$ \\
\hline Idle Time (\%) & 19.6 & 36.9 \\
\hline Stopsper Mile & 4.74 & 6.10 \\
\hline $\begin{array}{l}\text { Cha racteristic } \\
\left.\text { Acceleration (ft/s }{ }^{2}\right)\end{array}$ & 0.71 & 0.77 \\
\hline
\end{tabular}

Figure 1: OCTA Duty cycles and cycle statistics. 
The vehicle actual speed versus set point speed is analyzed post-test to determine whether the desired speed versus time cycle trace was met. This determination is made through a linear least-squares fit to the data and a slope near unity and high correlation coefficient $\left(\mathrm{R}^{2}\right.$ of 0.995 or greater) indicated that the driver followed the scheduled trace as closely as possible. This ensures that there is little test-to-test variability in the vehicle cycle, which can affect emissions and fuel economy results.

\subsection{Vehicle loading and coastdowns}

In order to accurately simulate the on-road operation of a transit bus in a stationary test, on-road vehicle loads were simulated using a chassis dynamometer directly connected to the drive hubs of each vehicle. Figure 2 below shows a transit bus being installed on the WVU chassis dynamometer. The simulated loads include vehicle inertia, aerodynamic drag and tire rolling resistance. Inertia was simulated using a combination of differently sized inertial flywheels that accurately reproduce the on-road inertia presented by the sum of the field-measured empty weight of the vehicle, one-half passenger load plus the driver (assuming $150 \mathrm{lbs}$ per passenger) and one-half tank of fuel. Aerodynamic drag and tire rolling resistance simulation was accomplished by controlling dynamometer loading to achieve appropriate deceleration rates across the driving speed spectrum.

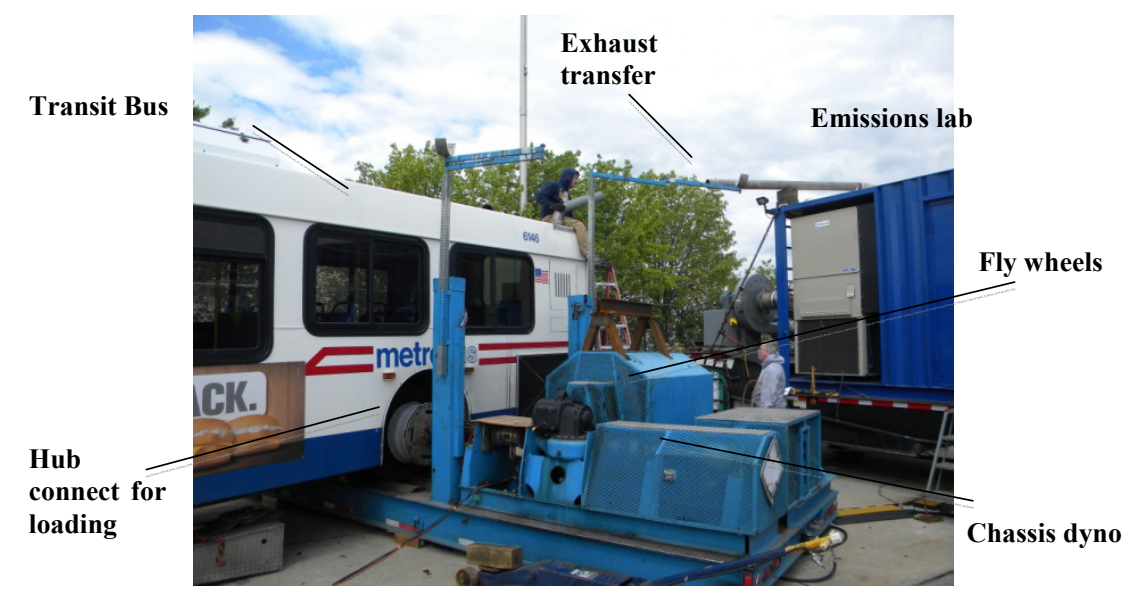

Figure 2: Transit bus installation on chassis dynamometer.

Dynamometer loading as a function of vehicle speed was determined by iteratively allowing the vehicle to coast from 50 miles per hour to a stop on the dynamometer while refining the dynamometer loading such that the coastdown profile matched a theoretical zero-grade (i.e. flat ground) coastdown profile determined using the frontal area of the bus and drag coefficient and tire rolling resistance coefficients typical for transit buses, as determined through extensive on-road coast down testing. The drag coefficient $\left(\mathrm{C}_{\mathrm{d}}\right)$ and rolling resistance 
coefficient $(\mu)$ used in all testing were 0.79 and 0.008 , respectively. These values are typical of transit buses and consistent with values used in previous test programs. Results of vehicle speed versus time from a typical coastdown run are included in Figure 3.

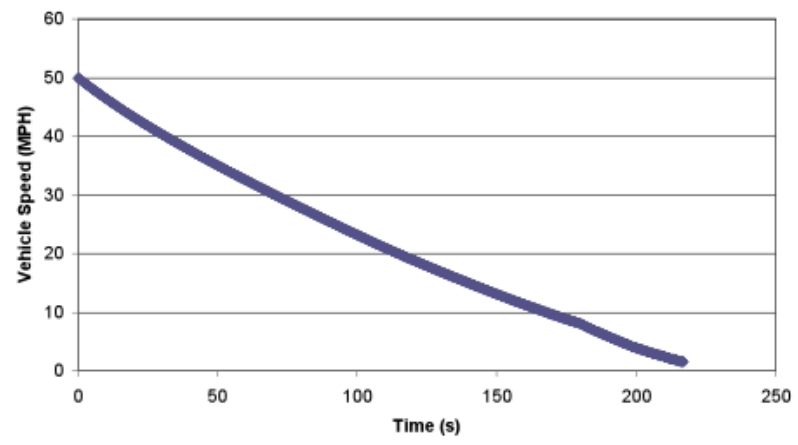

Figure 3: Sample speed versus time trace during coastdown.

The speed versus time data of the coastdown is manipulated by determining the time rate of change of momentum $(\mathrm{d}(\mathrm{mV}) / \mathrm{dt})$ of the vehicle which is balanced by the forces (air resistance and road friction) acting on the vehicle, as shown in Equation (1) below:

$$
\sum F=m a=m \frac{d V}{d t}=F_{\text {Drag }}+F_{\text {Friction }}=\frac{1}{2} \rho V^{2} A \cdot C_{d}+\mu \cdot m g
$$

where $m$ is the mass of the vehicle, $V$ is the velocity of the vehicle (time dependent), $t$ is time, $\rho$ is the air density, $A$ is the frontal area of the vehicle, $C_{d}$ is the drag coefficient, $\mu$ is the rolling resistance and $g$ is the acceleration due to gravity. Note that the drive cycles do not include any grade, so there is no force contribution from the force of gravity acting on the bus on a grade other than that due to road friction. Rearranging this equation into a non-dimensional form yields:

$$
\frac{d V}{d t} \cdot \frac{1}{g}=\frac{1}{2} \frac{\rho V^{2} A}{m g} \cdot C_{d}+\mu=m x+b
$$

As shown in Equation (2), rearranging the force balance into this form yields an equation where $M$ is the slope of a linear least-squares fit of a plot of $\mathrm{dV} / \mathrm{dt} * 1 / \mathrm{g}$ (y-axis value) vs. $1 / 2 \rho V^{2} A / m g$ (x-axis value) and $b$ is the intercept. Using the measured vehicle velocity on the chassis dyno, the calculated change in velocity with time, and the mass of the vehicle and frontal area, the linear fit to this data yields the drag coefficient $\left(\mathrm{C}_{\mathrm{d}}\right)$ as the slope and the rolling resistance 
( $\mu$ ) as the y-intercept, as shown in Figure 4. In the example, the drag coefficient (slope) is determined by the curve fit to be 0.79 and the rolling resistance is the intercept and is determined to be 0.008 , the target values for this vehicle. Scatter in the plot at lower velocity represent vehicle gearshifts typical of an automatic transmission.

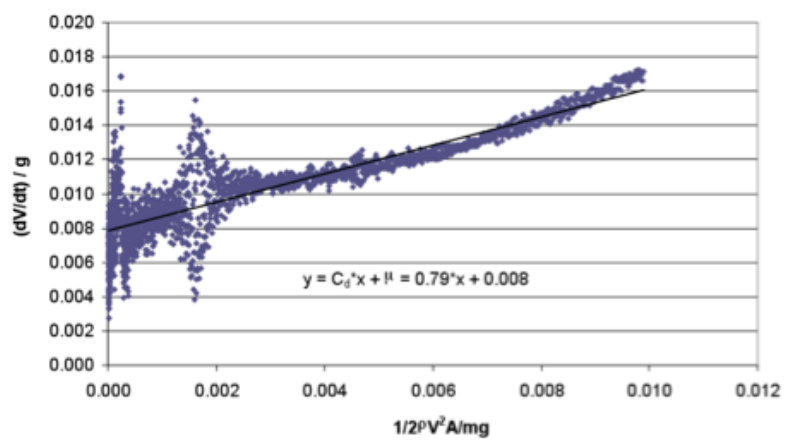

Figure 4: Determination of lab drag coefficient and rolling resistance example.

\section{Results and analysis}

\subsection{Emissions and fuel economy measurement}

Exhaust from each vehicle being tested was routed to a full-scale dilution tunnel where the exhaust was mixed with HEPA-filtered ambient air. A sample of the dilute exhaust was analyzed to determine the concentrations of carbon dioxide $\left(\mathrm{CO}_{2}\right)$, oxides of nitrogen (combination of nitrogen dioxide and nitric oxide reported as $\mathrm{NO}_{\mathrm{X}}$ ), carbon monoxide $(\mathrm{CO})$ and hydrocarbons $(\mathrm{HC})$. Procedures for calibrating, maintaining and operating the laboratory system contained in the United States EPA federal regulations (40 CFR Parts 86 and 1065) [8, 9] were followed throughout the test program.

A separate sample of the dilute exhaust was diluted further using a secondary dilution system before being passed through a mircrofiber filter to collect particulate matter (PM) emissions. PM Filters are pre- and post-weighed in a climate-controlled clean room on a microbalance after being conditioned under identical ambient conditions (temperature and humidity). The mass of particulate matter for each test was determined by subtracting the weight of the clean filter from that of the filter after particulate matter had been collected on its surface. This mass is then corrected for the dilution ratio (the amount of exhaust flow going through the filter compared to the total exhaust flow of the vehicle and dilution tunnel) to determine the weight of PM emitted by the engine during the cycle.

Fuel consumption was determined through two methods, gravimetrically and through a carbon chemical balance. For diesel and hybrid-electric diesel buses, 
the diesel fuel for the bus was supplied from a drum on a calibrated fuel weight scale. Total weight of fuel consumed was determined by analysis of initial and final fuel weight of the drum. In order to determine volume of fuel used (for miles per gallon fuel economy determination), specific gravity of the fuel was measured in-field using a hydrometer kit. In addition to gravimetric analysis, fuel consumption was calculated using a chemical carbon-balance methodology, which typically was within $5 \%$ of the gravimetric calculated value. For CNG bus testing, fuel consumption was determined only through carbon-balance, since gravimetric analysis was not possible.

All fuel economy (FE) data reported for the vehicles tested have been converted to \#2 diesel energy equivalent in order to compare FE between vehicles employing different fuels. In order to convert from a given fuel, the total energy into the engine from the fuel and distance traveled are held constant, so fuel economy can be thought of in terms of $\mathrm{kJ} / \mathrm{mile}$. In order to convert from one fuel to the other, the heating value (LHV) or total energy per mass $(\mathrm{kJ} / \mathrm{kg})$ of the fuels needs to be considered, as well as the density of the fuel to convert from mass to volume of fuel used. A sample of the diesel and CNG fuels used during testing were analyzed for composition and heating value. Equation (3) below is an example of converting fuel economy from \#1 diesel to \#2 diesel. For CNG, the FE was converted to MPG using the density of the fuel at standard temperature and pressure (STP).

$$
F E[M P G \# 2 \text { Diesel }]=F E[M P G \# 1 \text { Diesel }] \cdot \frac{L H V_{\# 2 \text { Diesel }} \cdot \text { Density }_{\# 2 \text { Diesel }}}{L H V_{\# 1 \text { Diesel }} \cdot \text { Density }_{\# 1 \text { Diesel }}}
$$

For testing of hybrid vehicles, the state-of-charge (SOC) of the energy storage system (ESS) was logged by continuous measurement of battery voltage and current magnitude and direction. This was done in order to determine the net energy change (NEC) of the ESS over the course of the drive cycle. SAE J2711, "Recommended Practice for Measuring Fuel Economy and Emissions of HybridElectric and Conventional Heavy-Duty Vehicles" [10] requires correction of emissions and fuel economy data if the NEC is greater than $1 \%$ over the test cycle. The total net battery work was calculated by integrating the power (voltage $\mathrm{x}$ current) throughout the test cycle over time and dividing by the total cycle energy to determine NEC. If this percentage is above $5 \%$, the test is invalid and must be repeated. For the reported data, all hybrid vehicles tests had a NEC of $1 \%$ or less, requiring no corrections to emissions or FE.

\subsection{Fuel economy and carbon dioxide emissions results}

Fuel economy and $\mathrm{CO}_{2}$ results are shown in Figure 5. As discussed above, FE numbers are presented in energy equivalent \#2 diesel gallons for comparative purposes between different propulsion technologies. Comparison of CNG $(60 \mathrm{ft}$ stoichiometric and $40 \mathrm{ft}$ lean burn) and equivalent size hybrid buses reveals that fuel consumption for CNG is approximately $45-50 \%$ higher than for the hybrids, as shown in the FE results, while $\mathrm{CO}_{2}$ emissions were approximately equal. 
Compared to conventional diesel, $\mathrm{CNG}$ is shown to have approximately $25 \%$ higher fuel consumption. $\mathrm{CNG}$ contains less carbon per unit of fuel energy (LHV) than petroleum fuels and therefore produces less $\mathrm{CO}_{2}$ for a given required energy input. From fuel analysis, hydrogen to carbon (H-C) ratios were 1.81 for diesel and 3.85 for $\mathrm{CNG}$, while lower heating values were $42.73 \mathrm{MJ} / \mathrm{kg}$ for diesel and $49.83 \mathrm{MJ} / \mathrm{kg}$ for $\mathrm{CNG}$. A combustion analysis reveals that diesel fuel produces $15 \%$ more $\mathrm{CO}_{2}$ per unit mass of fuel and $34 \%$ more $\mathrm{CO}_{2}$ per unit energy ( $\mathrm{LHV}$ ) than $\mathrm{CNG}$. The overall $\mathrm{CO}_{2}$ advantage of $\mathrm{CNG}$ is lower than that as diesel combustion achieves higher compression ratios (16:1-18:1) than $\mathrm{CNG}$ (10:1-12:1) with higher conversion efficiencies, and CNG buses are heavier than diesels. When compared with diesel, CNG fueled transit buses have been measured to produce up to $35 \%$ less $\mathrm{CO}_{2}$ emissions [11], in the current work this value was measured to be approximately $12 \%$. Hybrid vehicles, on the other hand, take advantage of regenerative braking and improved engine operation to reduce fuel consumption. Interestingly, this advantage over diesel is shown to be approximately $20 \%$ for MY 2003-2006 buses, while the hybrid advantage of the new MY buses was measured as only approximately 5\%, likely due to the increased weight of the newer hybrid buses.

Another significant parameter to consider when comparing $\mathrm{CNG}$ and diesel buses is vehicle curb weight. A $40 \mathrm{ft} \mathrm{CNG}$ bus is 2,000 to 3,000 lb heavier than

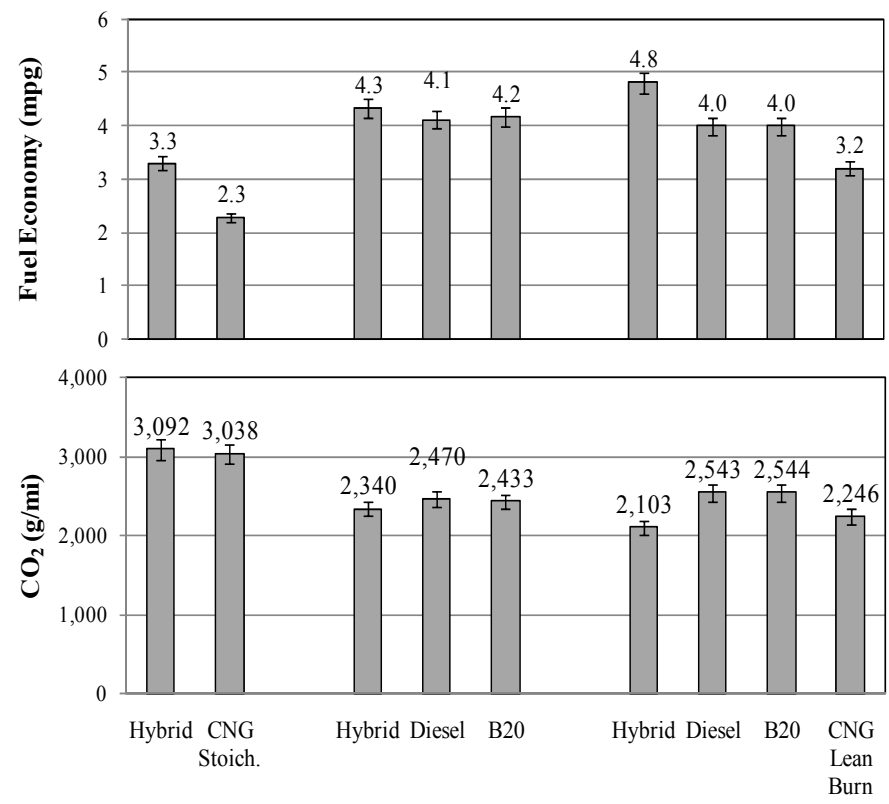

$60 \mathrm{ft}$ - MY 2007-2009

$40 \mathrm{ft}$ - MY 2007-2009

$40 \mathrm{ft}$ - MY 2003-2006

Figure 5: OCTA Cycle fuel economy and $\mathrm{CO}_{2}$ emissions. 
the conventional diesel counterpart. CNGs and diesel-hybrids, on the other hand, have equivalent weights; in the CNGs the extra weight comes from the high-pressure fuel tanks while in the hybrids it is attributed to the hybrid battery pack. Considering all of these factors together make the $\mathrm{CO}_{2}$ advantage, comparing against the conventional diesel baseline, from the hybrid architecture equivalent to the advantage from the $\mathrm{CNG}$ technology. This conclusion holds for both of the CNG technologies studied, lean burn and stoichiometric.

The impact of biodiesel fuel on FE was not significant. The difference in heating value between B20 (20\%/80\% blend of biodiesel and diesel) and diesel fuels was less than $2 \%$. Similar results were obtained for $\mathrm{CO}_{2}$ emissions. Even though tailpipe $\mathrm{CO}_{2}$ emissions from diesel and B20 biodiesel fueled buses were equivalent, the potential of biodiesel blends is the reduction of "well-to-wheel" carbon dioxide emissions, which includes fuel production, shipping, etc. Being a feedstock based fuel; biodiesel reduces the net carbon footprint when compared to petroleum diesel. A "well-to-wheel" analysis, performed with GREET software from U.S. Argonne National Laboratory, reveals that the B20 blend has the potential of reducing the $\mathrm{CO}_{2}$ footprint by $15 \%$.

\subsection{Regulated emissions results}

Figure 6 presents regulated emissions $\left(\mathrm{NO}_{\mathrm{x}}, \mathrm{PM}, \mathrm{HC}\right.$ and $\left.\mathrm{CO}\right)$ for the test vehicles. $\mathrm{NO}_{\mathrm{x}}$ emissions for $40 \mathrm{ft}$, model year (MY) 2003-2006 buses were higher for the CNGs, followed by biodiesel, diesel, and hybrid with the lowest. $\mathrm{NO}_{\mathrm{x}}$ emissions were slightly higher for B20 than for diesel, but without statistical significance (as shown by the error bars). Introduction of lower $\mathrm{NO}_{\mathrm{x}}$ certification engines (2007-2009) reduced $\mathrm{NO}_{\mathrm{x}}$ by nearly $40 \%$ from the earlier $\mathrm{B} 20$ and diesel levels, while the reduction was marginal for the hybrids.

The effect on regulated emissions of employing B20 biodiesel is also demonstrated in Figure 6. The differences are seen primarily in the $\mathrm{NO}_{\mathrm{x}}$ and $\mathrm{PM}$ emissions, while $\mathrm{HC}$ and $\mathrm{CO}$ had low values for both $\mathrm{B} 20$ and diesel. Employing B20 increased $\mathrm{NO}_{\mathrm{x}}$ emissions slightly, approximately 10\% for MY 2003-2006 buses and 5\% for newer MY buses. PM emissions decreased nearly $20 \%$ on older MY buses that have significantly higher PM emissions than 2007 and later MY vehicles equipped with more advanced diesel particulate filters (DPFs). The decreases in PM for newer MY buses is approximately $50 \%$, but for both diesel and B20, the PM levels are extremely low.

Implementation of DPFs on post 2007 buses brought PM emissions levels to near zero values. The MY 2003-2006 diesel hybrid was also DPF equipped, as evidenced by the low PM values measured. Hydrocarbon emissions from diesel buses also had near zero values while they were significant from CNGs. The DPFs also react on carbon monoxide emissions, with extremely low measured values. The $\mathrm{CNG}$ stoichiometric combustion showed $\mathrm{CO}$ emissions levels 50 times higher than the lean burn CNG combustion buses. This was not expected, as the stoichiometric $\mathrm{CNG}$ buses have a 3-way catalyst that is used in rich-burn or stoichiometric engines for simultaneous conversion of oxides of nitrogen $\left(\mathrm{NO}_{\mathrm{x}}\right)$, carbon monoxide $(\mathrm{CO})$ and hydrocarbons $(\mathrm{HC})$. 

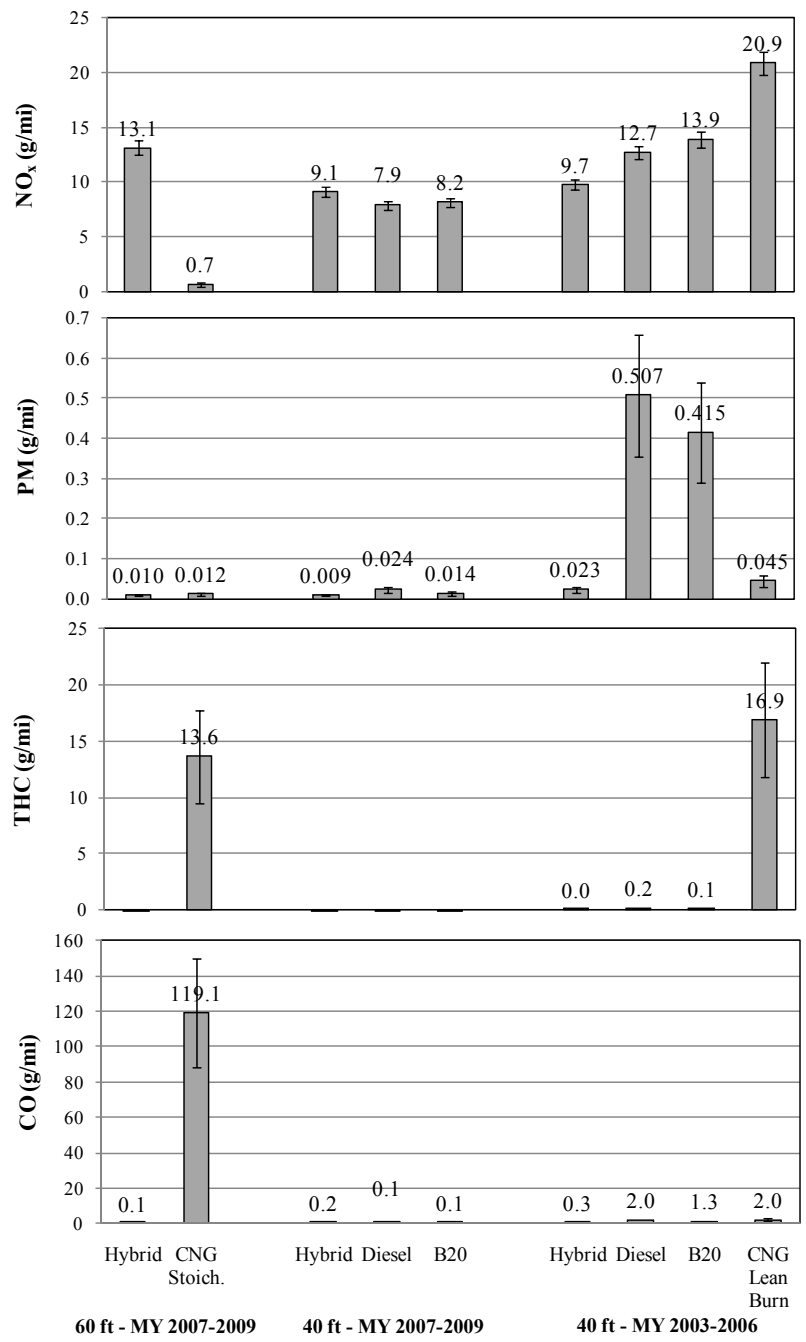

Figure 6: OCTA Cycle distance-specific emissions.

A direct comparison between the lean burn and stoichiometric CNG buses is complicated by the fact that the vehicles were of different size (40 ft vs. $60 \mathrm{ft}$ ). As a method of comparison, the total emissions were normalized by engine work (in break horsepower-hours), as shown in Figure 7. It should be noted that both Figures 7 and 8 have been scaled to plot different emissions magnitudes on the same plot. Figure 7 shows a $20 \%$ increase in brake-specific $\mathrm{CO}_{2}$ emissions for the stoichiometric engine compared to the lean burn strategy. This result is due to incomplete combustion and to the higher combustion temperature that leads to higher heat losses in the stoichiometric engine [12]. The 3-way catalyst on the 
stoichiometric bus resulted in a reduction of $97 \%$ in $\mathrm{NO}_{\mathrm{x}}$ emissions, $80 \%$ in $\mathrm{PM}$, and $40 \%$ in $\mathrm{HC}$.

Figure 8 presents a comparison with regard to ridership between standard (40 ft) and articulated (60 ft) hybrid buses, MY 2007-2009. Emissions are in grams per passenger-mile and fuel consumption (FC) in gallons per passengermile. The figure shows that implementation of articulated routes can yield a reduction of $15 \%$ in fuel consumption per passenger-mile at half seated occupation. The improvement can be as high as $25 \%$ with full load. The effect on $\mathrm{CO}_{2}$ is equivalent to the effect on $\mathrm{FC}$; the reductions shown on other emissions are within the experimental uncertainty.

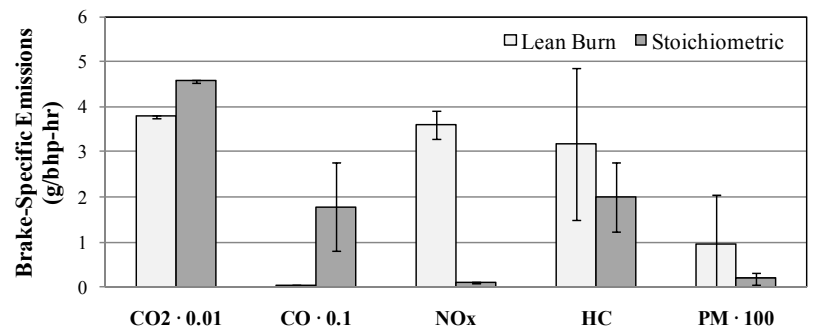

Figure 7: Scaled brake-specific emissions for lean burn and stoichiometric CNGs.

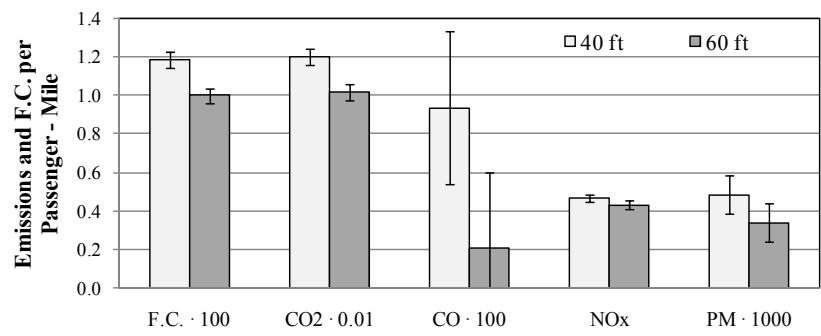

Figure 8: $\quad$ Standard versus articulated bus comparison.

\section{Experimental uncertainty}

Experimental uncertainty of the emissions and FE data reported in this paper is a function of bias uncertainty and measurement uncertainty. Bias uncertainty is a function of errors in the measurements devices (analyzers, thermocouples, flow meters, etc.), while measurement uncertainty is a function of test-to-test variability, either from test conditions or human error. Since the reported results are comparative and the laboratory equipment and procedures are consistent between the various vehicles and cycles tested, the bias uncertainty is essentially the same for all tests and does not present a significant contribution to 
uncertainty. Measurement uncertainty was determined through analysis of the experimental values for repeat tests for a specific vehicle and cycle. Absolute values were determined through margin of error analysis, m.e. $=t^{*} \cdot \sigma / \sqrt{n}[13]$, where m.e. is margin of error, $\sigma$ is standard deviation, $n$ is number of tests, and $t^{*}$ is the $t$ distribution critical value corresponding to $n-1$ degrees of freedom and a confidence level of $95 \%$. Relative values (\%) were obtained with the margin of error relative to the average. Uncertainty is reflected in the reported emissions and $\mathrm{FE}$ results in Figures 5, 6, 7 and 8 with error bars.

Average uncertainty in fuel economy and $\mathrm{CO}_{2}$ emissions was estimated to be $4 \%$, with individual values ranging from $2 \%$ to $9 \%$. This was the case when 3 tests were done; on the other hand, when 4 or 5 tests were performed, uncertainty in fuel economy and $\mathrm{CO}_{2}$ emissions was reduced to $1 \%$ to $2 \%$. The uncertainty levels on a percentage basis for $\mathrm{NO}_{\mathrm{x}}, \mathrm{CO}$, and $\mathrm{HC}$ emissions were dependent on the magnitude of the corresponding species. With tightening emissions regulations and new technologies having very low emissions values, tailpipe emissions can differ from one to two orders of magnitude between technologies. The lower end of the spectrum presents a high percentage uncertainty while uncertainty for the high end is lower. Uncertainty in $\mathrm{NO}_{\mathrm{x}}$ emissions was estimated to be $5 \%$ when distance specific emissions were on the order of 1 to 10 $\mathrm{g} / \mathrm{mile}$, and $30 \%$ where they were of order $0.1 \mathrm{~g} / \mathrm{mile}$. Average PM emissions uncertainty was around $30 \%$, although it should be noted that due to the diesel and hybrid vehicles being equipped with particulate filters and CNG vehicles having extremely low PM emissions, the uncertainty in PM measurement is high.

All post 2007 diesel buses, which were DPF equipped, presented HC emissions below the detection limit of the test bench, and thus uncertainty was not determined. HC emissions for the CNG buses and the 2003-2006 diesel oxidation catalyst (DOC) equipped diesel buses had an average uncertainty of $30 \%$. Uncertainty in carbon monoxide was high due run-to-run variation that is likely due to variations in the efficiency of the catalyst from test to test.

\section{Conclusions and recommendations}

The current work presents fuel economy and emissions results for conventional diesel, diesel-electric hybrid, biodiesel and natural gas powered transit buses. The primary focus was to present the benefits in fuel economy and potential decreases in $\mathrm{CO}_{2}$ (a greenhouse gas $(\mathrm{GHG})$ ), as well as reporting the emissions levels of other regulated emissions, including $\mathrm{NO}_{\mathrm{x}}$ (an indirect $\mathrm{GHG}$ ).

Results showed that hybrid-electric diesel and $\mathrm{CNG}$ buses yield significant reductions in $\mathrm{CO}_{2}$ emissions, approximately 10-20\% lower than conventional diesel. Stoichiometric $\mathrm{CNG}$ buses demonstrated extremely low emissions of $\mathrm{NO}_{\mathrm{x}}$, while lean burn $\mathrm{CNG}$ had the highest $\mathrm{NO}_{\mathrm{x}}$ emissions, approximately twice that of hybrid technologies and conventional diesel engines, which have approximately the same levels of $\mathrm{NO}_{\mathrm{x}}$. Fuel economy of the various technologies was compared on a \#2 diesel basis. As expected, the hybridelectric technology demonstrated the highest fuel economy, while CNG has the lowest fuel economy. When compared on a per passenger basis, the $60 \mathrm{ft}$ 
stoichiometric $\mathrm{CNG}$ buses showed a $15-20 \%$ lower fuel consumption (gal/passenger-mile), and $20 \%$ lower $\mathrm{CO}_{2}$ emissions (grams/passenger-mile) than the $40 \mathrm{ft}$ lean burn CNG buses, demonstrating the value of employing $60 \mathrm{ft}$ articulated buses in transit service. The use of biodiesel (B20) demonstrated no discernable differences in fuel economy, while showing slightly higher $\mathrm{NO}_{\mathrm{x}}$ emissions levels and significantly lower PM compared to conventional diesel. A well-to-wheel analysis revealed that the $\mathrm{B} 20$ blend has the potential of reducing the $\mathrm{CO}_{2}$ footprint by $15 \%$, although differences in $\mathrm{CO}_{2}$ emissions from diesel engine combustion are within the measurement uncertainty.

With the advent of the advanced bus technologies presented in this paper, the only emissions that remain relevant, with any significant emission levels are $\mathrm{CO}_{2}$ and $\mathrm{NO}_{\mathrm{x}}$. Emissions levels of $\mathrm{HC}$ and $\mathrm{CO}$ were demonstrated to be near zero for all technologies with the exception of the $\mathrm{CNG}$ buses. PM emissions were shown to be extremely low for all vehicles except the older MY diesel buses.

The recommendations on choice of the optimal vehicle technology resulting from this work are complicated by the dependency on average driving cycle for specific application and economics of vehicle purchase. However, one key aspect is the need to look at emissions and FE on a per passenger basis.

The current work presented data for a single drive cycle (OCTA) only. The data from this program have been added to the extensive database of emissions data maintained by the WVU CAFEE. In order to perform an analysis including economics of vehicle purchase, WVU has developed an Integrated Bus Information System (IBIS) database [14] online and will be developing a lifecycle cost (LCC) model website under funding from U.S. Federal Transit Administration (FTA). Application of the LCC model and analysis of the effects of vehicle drive cycle to the current data set are planned as a potential future publication.

\section{Acknowledgements}

The authors would like to acknowledge the support of the Washington Metropolitan Area Transit Authority (WMATA), the Central Florida Regional Transportation Authority (LYNX), the U.S. Department of Transportation (DOT)-Federal Transit Administration (FTA) and the U.S. Department of Energy (DOE) in conducting this research. We would especially like to acknowledge the support and assistance of Mr. Vernon Lyght and WMATA in providing the test site and vehicles comprising the majority of the research contained in this work.

\section{References}

[1] Wayne, W.S., Sandoval, J.A. \& Clark, N.N., Emissions Benefits from Alternative Fuels and Advanced Technology in the U.S. Transit Bus Fleet. Energy \& Environment, 20 (4), pp. 497-515, 2009.

[2] Gouge, B., Ries, F.J. \& Dowlatabadi, H., Spatial Distribution of Diesel Transit Bus Emissions and Urban Populations: Implications of Coincidence 
and Scale on Exposure. Environ. Sci. Technol., 44 (18), pp 7163-7168, 2010.

[3] Wu, Y., Carder, D.K., Shade, B.C., Atkinson, R.J., Clark, N.N. \& Gautam, M., A CFR1065-Compliant Transportable/On-Road Low Emissions Measurement Laboratory with Dual Primary Full-Flow Dilution Tunnels. Proc. of the ASME 2009 Internal Combustion Engine Division Spring Tech. Conf., pp 399-410, 2009.

[4] Kahn, ABM S., Clark, N.N., Wayne, W.S., Thompson, G.J., Gautam, M. \& Lyons, D.W., Regulated and Non-Regulated Emissions and Fuel Economy from Conventional Diesel, Hybrid-electric Diesel and Natural Gas Buses. Journal of the Transportation Research Forum, 47(3), pp. 105-126, 2008.

[5] Clark, N.N., Rivero-Borrell, E., McKain, D., Paramo, V.H., Wayne, W.S., Vergara, W., Barnett, R., Gautam, M., Thompson, G.J., Lyons, D.W. \& Schipper, L., Evaluation of Emissions from New and In-Use Transit Buses in Mexico City. Transportation Research Record, 1987, pp. 42-53, 2006.

[6] Clark, N.N., McKain, D.L., Sindler, P., Jarrett, R., Nuszkowski, J.P., Gautam, M., Wayne, W.S. \& Thompson, G.J., Comparative Emissions from Diesel and Biodiesel Fueled Buses from 2002 to 2008 Model Years. SAE Technical Paper Series, 2010-01-1967, 2010.

[7] Clark, N.N., Prucz, J.C., Gautam, M. \& Lyons, D.W., The West Virginia University Heavy Duty Vehicle Emissions Database as a Resource for Inventory and Comparative Studies. SAE Technical Paper Series, 2000-012854, 2000.

[8] Code of Federal Regulations. Title 40: Protection of Environment, Part 86: Control of emissions from new and in-use highway vehicles and engines. U.S. Government Printing Office, Washington DC, 2006.

[9] Code of Federal Regulations. Title 40: Protection of Environment, Part 1065: Engine Testing Procedures. U.S. Government Printing Office, Washington DC, 2006.

[10] "Recommended practice for measuring fuel economy and emissions of hybrid-electric and conventional heavy-duty vehicles. SAE J2711. Surface Vehicle Recommended Practice." SAE International Publications, Warrendale PA, 2002.

[11] Melendez, M., Taylor, J., Zuboy, J., Wayne, W.S. \& Smith, D., Emission Testing of Washington Metropolitan Area Transit Authority (WMATA) Natural Gas and Diesel Transit Buses. NREL/TP Technical Report 54036355, Golden, CO, 2005.

[12] Faiz, A., Weaver, C.S. \& Walsh, M.P., Air Pollution from Motor Vehicles: Standards and Technologies for Controlling Emissions, The World Bank: Washington DC, pp. 197, 1996.

[13] Moore, D.D. \& McCabe, G.P., Introduction to the Practice of Statistics, Fifth Edition, Freeman: New York, pp. 452, 2006.

[14] http://ibis.wvu.edu/ 